\title{
FONOAUDIOLOGIA E HUMANIZAÇÃO: PERCEPÇÃO DE FONOAUDIÓLOGAS DE UM HOSPITAL PÚBLICO
}

\author{
Speech and language therapy and humanization: \\ perception of speech and language therapist of a public hospital
}

\author{
Sorel Herrera Celín (1), Flávia Horta Azevedo Gobbi ${ }^{(2)}$, Stela Maris Aguiar Lemos ${ }^{(3)}$
}

\begin{abstract}
RESUMO
Objetivo: investigar o conhecimento e aplicação da Política Nacional de Humanização por fonoaudiólogos de um hospital público de Belo Horizonte. - Método: trata-se de um estudo qualitativo que teve como instrumento de coleta de dados um formulário elaborado pelas pesquisadoras. A amostra foi composta por 25 fonoaudiólogas de um hospital público. Foi realizada análise quantitativa das questões de caracterização da amostra e análise quanti-qualitativa de conteúdo na qual foram identificadas e elencadas as categorias de análise e a frequência de ocorrência dos conteúdos e expressões para as questões discursivas. Resultados: na análise quantitativa, percebeu-se que $68 \%$ das fonoaudiólogas eram formadas há mais de cinco anos; $88 \%$ tinham pós-graduação; 56\% atuavam na área de Audiologia; $52 \%$ atuavam também em instituições privadas e $60 \%$ referiram conhecer a $\mathrm{PNH}$. $\mathrm{Na}$ análise qualitativa, as necessidades/demandas apontadas para garantia do atendimento humanizado constaram dos eixos temáticos gestão e organização dos serviços de saúde, instrumentalização do trabalhador da saúde, multiprofissional e intersetorial, além do respeito às demandas e direitos do usuário. Conclusão: o conceito de humanização apresentado pelas fonoaudiólogas está em consonância com o descrito na PNH. E quanto aos eixos para garantia da atenção humanizada tomando com referência a instituição, o usuário e o profissional, as entrevistadas citaram parcialmente os princípios da Política Nacional de Humanização.
\end{abstract}

DESCRITORES: Humanização da Assistência; Saúde Pública; Sistema Único de Saúde; Atenção Terciária à Saúde; Conhecimentos, Atitudes e Prática em Saúde

\section{INTRODUÇÃO}

Compreender que o termo humanização deriva da palavra humanizar, que significa "tornar humano, educado, afável, civilizado" é fundamental para compreender as políticas e programas de humanização da assistência em saúde.

A humanização da atenção em saúde permeia a relação entre sujeitos de forma responsável,

(1) Fonoaudióloga graduada pela Universidade Federal de Minas Gerais (UFMG), Belo Horizonte, MG, Brasil.

(2) Fonoaudióloga; Mestre em Fonoaudiologia pela Pontifica Universidade Católica de São Paulo - PUC-SP, São Paulo,Brasil.

(3) Fonoaudióloga; Professora Adjunto do Departamento de Fonoaudiologia da Universidade Federal de Minas Gerais - UFMG; Doutora em Ciências pela universidade Federal de São Paulo - UNIFESP, São Paulo,Brasil.

Conflito de interesses: inexistente compromissada e acolhedora, respeitando direitos e deveres de cada um. Atualmente, as relações estabelecidas entre os sujeitos nos espaços de saúde e doença por vezes carecem de tais conceitos. Deste modo, tornam-se relevantes procedimentos humanizadores em gestão, assistência e produção do cuidado em saúde para o aprimoramento da qualidade dos recursos humanos e do acesso aos serviços ${ }^{1}$.

A integralidade na assistência e prevenção em saúde busca oferecer ao indivíduo um atendimento global, que alivie a queixa, diminua o sofrimento, intervir em aspectos que possam orientar e ampliar o conhecimento do profissional sobre o indivíduo tratado e orientar a organização dos serviços ${ }^{1}$.

A Política Nacional de Humanização (PNH), criada em 2004, procura melhorar de forma sistematizada a gestão e a prestação de saúde nos serviços públicos e privados do Brasil, tendo como 
protagonistas os usuários, os profissionais de saúde e a área administrativa das instituições. Os princípios norteadores de tal política valorizam, estimulam e favorecem a subjetividade e o campo social nas práticas de atenção e gestão em saúde. Esta política ressalta estratégias e prioridades para desenvolvimento de programas humanizadores dentro e fora das instituições de saúde. ${ }^{2}$

No Sistema Único de Saúde (SUS) existem programas, projetos, atividades e ações, com o tema de humanização, mas estudos apontam para erros, que levam a verticalização, fragmentação e banalização de tais programas ${ }^{2,3}$. Deste modo, a política nacional de humanização propõe mudanças nos modelos de atenção e gestão em saúde, amparando usuários e trabalhadores, garantindo para todos espaço físico, administrativo e ambiental digno, para desenvolver da melhor forma seus papéis dentro do SUS ${ }^{2,3}$.

A assistência humanizada do cuidador possibilita a este e a seu paciente uma convivência mais próxima, que permite a troca de experiências, a solução de problemas e o conhecimento da limitação do outro, mesmo que a comunicação entre os participantes não seja verbal ${ }^{4}$.

A literatura mostra que as instituições de assistência pública de saúde contribuem para a quebra do diálogo entre os usuários e a instituição, por terem a certeza de executar de forma correta os princípios, acreditando saber de antemão o que o usuário precisa. Esta forma de preencher as necessidades em saúde faz com que o usuário não participe de forma ativa junto à equipe do sistema ${ }^{5}$.

Para garantir práticas humanizadoras em serviços de saúde é importante buscar a qualificação de trabalhadores e serviços, a atualização dos conceitos e a inclusão da PNH em momentos de planejamento e avaliação dos serviços ${ }^{6}$.

Cabe ressaltar que existe relação entre ação humanizadora e ética no trabalho, que coloca a ação humanizadora como uma das bases da ética profissional. E para que essa relação seja cumprida adequadamente, deve existir nas instituições uma comunicação ampla e horizontal que proporcione a todos os integrantes participarem das decisões, planejamentos e educação na assistência de ambientes humanizados, respeitando as singularidades ou diferenças de cada indivíduo ou grupo ${ }^{7}$.

A humanização busca resgatar a subjetividade em saúde, apresentando como reflexão a relação médico-paciente. Discute, dessa forma, o atual objetivo dos profissionais que têm uma prática de trabalho mais tecnológica e menos humanizada ${ }^{8}$.

Assim, é de suma importância a investigação sobre a humanização dos serviços saúde, incluindo os constituídos por Fonoaudiólogos. Além disso, grande parte do processo de humanização perpassa habilidades e atitudes comunicativas que são escopo de estudo e intervenção do fonoaudiólogo.

O presente estudo busca dados sobre o conceito de humanização e sobre as percepções de fonoaudiólogos quanto às necessidades para garantia do atendimento humanizado, tendo como referência a instituição, o ambiente de trabalho, o usuário e o profissional de saúde. Pretende-se, ainda, subsidiar a reflexão dos fonoaudiólogos e/ou profissionais de saúde quanto ao cumprimento da Política Nacional de Humanização como base do sucesso de procedimentos terapêutico e, principalmente, como exercício da cidadania.

Este trabalho teve como objetivo geral investigar o conhecimento e aplicação da Política Nacional de Humanização por fonoaudiólogos de um hospital público de Belo Horizonte.

Para tanto os objetivos específicos foram:

1. Caracterizar a amostra quanto à formação, à área de atuação e à vinculação ao Hospital das Clínicas e outras instituições;

2. Verificar a percepção da amostra quanto ao conhecimento da Política Nacional de Humanização;

3. Identificar, como categorias de análise, o conceito de humanização e a percepção dos fonoaudiólogos quanto às demandas da instituição, do ambiente, do usuário e do profissional de saúde, para garantia de atendimento humanizado.

\section{MÉTODO}

Trata-se de estudo transversal observacional com amostra de conveniência com análise de base quantitativa e qualitativa. O instrumento de coleta de dados foi elaborado pelas pesquisadoras e tratase de um formulário dividido em duas partes. A primeira parte teve como objetivo a caracterização da amostra por meio de dados sócio demográficos, tempo de formação, tipo de vínculo com o hospital onde foi realizada a pesquisa e outras instituições e área de atuação.

$\mathrm{Na}$ segunda parte do instrumento constavam questões relacionadas ao conceito de humanização e aos princípios da Política Nacional de Humanização (PHN), que visaram identificar os conhecimentos e as percepções dos fonoaudiólogos quanto ao atendimento humanizado, a saber:

1. Qual é seu conceito de Humanização?

2. O que você considera necessário para um atendimento Humanizado do ponto de vista:

a. Da instituição:

b. Do ambiente de trabalho:

c. Do usuário:

d. Do profissional: 
Participaram do estudo 25 das 28 fonoaudiólogas vinculadas a um hospital de ensino de Belo Horizonte - MG, pois 2 recusaram-se e 1 efetuou a entrega do formulário após a análise dos dados. Os participantes foram contatados por telefone, e-mail ou visita ao local de trabalho. Em seguida foram agendados encontros no próprio local de trabalho para explicação da pesquisa, assinatura do Termo de Consentimento Livre e Esclarecido (TCLE) e entrega instrumento de coleta de dados (formulário). Cada profissional teve a liberdade de devolver o formulário quando melhor lhe conviesse mediante um prazo estipulado.

Foram considerados como critérios de inclusão: o fonoaudiólogo que exerce seu trabalho no hospital de ensino localizado na cidade de Belo Horizonte ter lido e assinado o termo de consentimento livre e esclarecido mostrando que concordou em participar do presente estudo. Como critério de exclusão foi considerado o preenchimento do formulário com menos de $90 \%$ de questões respondidas.

O presente estudo foi analisado e aprovado pelo Comitê de Ética em Pesquisa da Universidade Federal de Minas Gerais sob parecer $\mathrm{n}^{\circ}$ ETIC181/07.

Para análise dos formulários, as respostas foram digitadas em um banco de dados e conferidas.
Foi realizada análise descritiva da distribuição de frequência de todas as variáveis categóricas. Para as questões abertas, optou-se por utilizar a análise de conteúdo ${ }^{9}$ dos discursos, metodologia de análise de textos que parte de uma perspectiva quantitativa, analisando-se numericamente a frequência de ocorrência de determinados termos, construções ou referências. Após a seleção das categorias a serem analisadas em cada questão, verificou-se a sua frequência de ocorrência (advento) nos discursos dos sujeitos de termos e expressões.

\section{RESULTADOS}

Os dados revelaram que $16 \%$ das entrevistadas são graduadas em fonoaudiologia de 1 a 5 anos, outros $16 \%$ de 3 a 5 anos e $68 \%$ há mais de 5 anos.

A maioria das entrevistadas (56\%) teve ingresso na instituição participante da pesquisa (hospital de ensino) por meio de concurso público.

Em relação à formação profissional, $36 \%$ da amostra possui especialização, $48 \%$ mestrado e $16 \%$ doutorado. Os dados referentes às áreas de atuação da amostra estão apresentados na figura 1 e evidenciam que a maioria atua na área de audiologia.

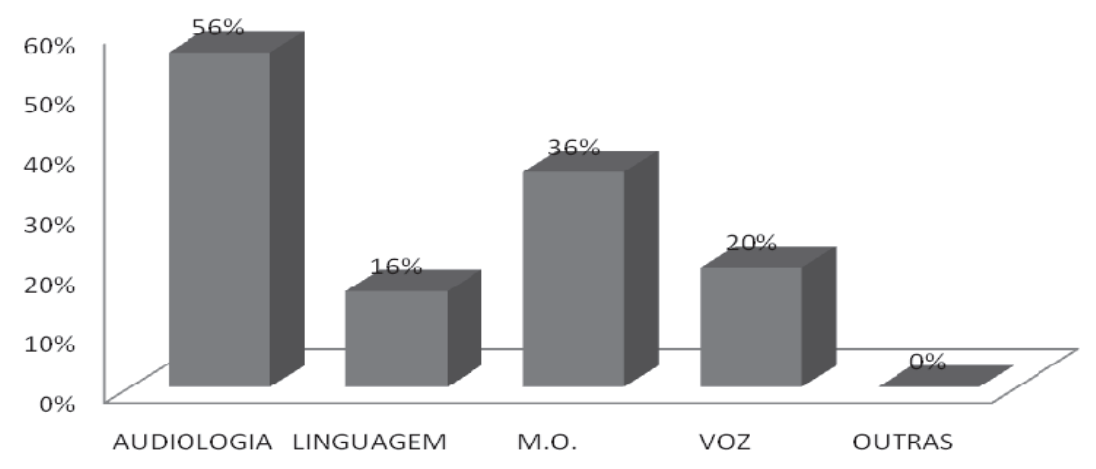

NOTA: A soma do porcentual ultrapassa $100 \%$ porque houve mais de uma resposta para o mesmo sujeito.

Figura 1 - Demonstrativo DA área de atuação das fonoaudiologas entrevistadas ( $n=25)$

A figura 2 mostra aspectos das instituições onde as entrevistadas trabalham, além do hospital de ensino. Os resultados evidenciam que a maioria está vinculada à rede privada.

Em relação ao conhecimento da Política Nacional de Humanização $60 \%$ das fonoaudiólogas relataram conhecê-la e as categorias emergentes foram atendimento integral, acolhimento e qualidade de vida, conforme apresentado na figura 3.
Quanto às necessidades/demandas para garantia do atendimento humanizado tendo como referência a instituição, as categorias identificadas baseadas nas respostas das entrevistadas foram: acesso e organização do serviço, relação entre os trabalhadores e equipes, instrumentalização/ capacitação de profissionais e equipes, ações de promoção da saúde, valorização do profissional e infraestrutura para o trabalhador em saúde, conforme consta na figura 4. 


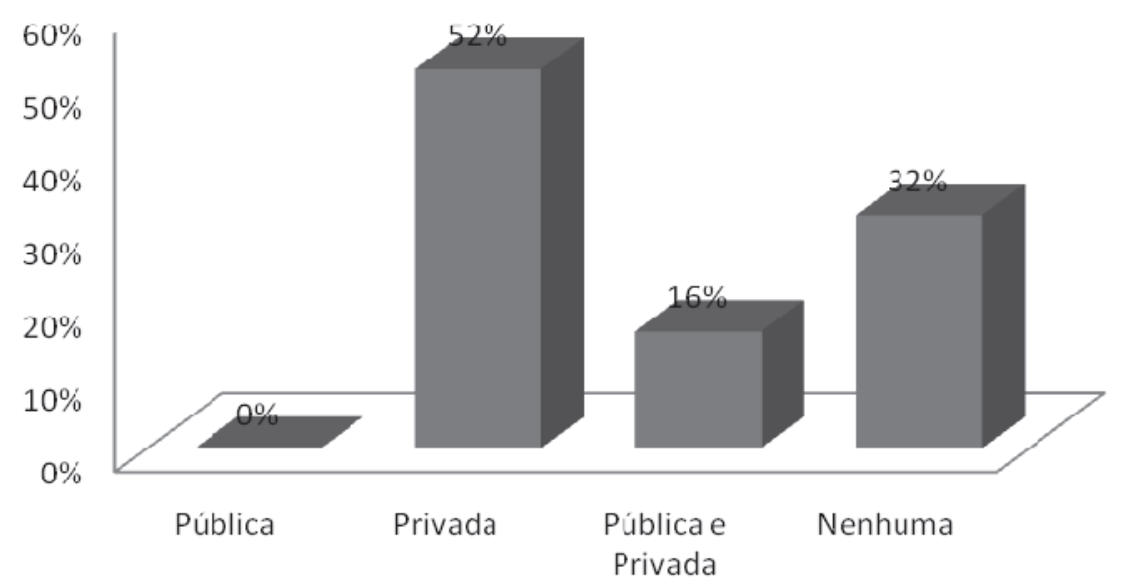

Figura 2 - Demonstrativo DOS tipos de instituições onde trabalham as entrevistadas, além do HC/ UFMG ( $\mathrm{N}=25)$

\begin{tabular}{|c|c|c|c|}
\hline Categorias & Conteúdos & $\mathbf{N}$ & Vinhetas \\
\hline $\begin{array}{l}\text { Atendimento } \\
\text { integral }\end{array}$ & $\begin{array}{l}\text { Atendimento integral } \\
\text { Considerar o nível físico, ambiental, } \\
\text { emocional } \\
\text { Paciente visto como um todo } \\
\text { Aspectos sociais, emocionais, } \\
\text { culturais etc } \\
\text { Integridade do indivíduo } \\
\text { Aspecto psíquico-social }\end{array}$ & 9 & $\begin{array}{c}\text { "O atendimento "Humanizado" deve } \\
\text { possibilitar a atenção integral, } \\
\text { equânime e universal ao usuário e a } \\
\text { satisfação/efetividades do profissional } \\
\text { de saúde, incluindo a organização do } \\
\text { trabalho". }\end{array}$ \\
\hline $\begin{array}{l}\text { Qualidade de } \\
\text { vida }\end{array}$ & $\begin{array}{l}\text { Melhoria da qualidade de vida } \\
\text { Qualidade de vida } \\
\text { Atendendo com qualidade }\end{array}$ & 4 & $\begin{array}{c}\text { "Respeito e busca pela melhoria da } \\
\text { qualidade de vida deste paciente e } \\
\text { seus familiares". }\end{array}$ \\
\hline Acolhimento & $\begin{array}{l}\text { Atendimento mais acolhedor } \\
\text { Processo de acolhimento } \\
\text { Acolhimento do usuário }\end{array}$ & 6 & $\begin{array}{c}\text { "A humanização deve ser pautada no } \\
\text { contato humano de forma acolhedora } \\
\text { e contemplar a integralidade do } \\
\text { indivíduo". }\end{array}$ \\
\hline
\end{tabular}

Legenda: $\mathrm{N}$ - número de ocorrências

Figura 3 - Relação das categorias, conteúdos e apresentação de vinhetas elencadas no relato das fonoaudiólogas quanto ao conceito de humanização 


\begin{tabular}{|c|c|c|c|c|}
\hline Categorias & \multicolumn{2}{|c|}{ Conteúdos } & $\mathrm{N}$ & Vinhetas \\
\hline $\begin{array}{l}\text { Acesso e } \\
\text { Organização do } \\
\text { serviço }\end{array}$ & $\begin{array}{l}\text { - Qualidades no } \\
\text { sentido de detectar } \\
\text { como os pacientes } \\
\text { estão sendo } \\
\text { atendidos } \\
\text { - Melhoria no processo } \\
\text { burocrático } \\
\text { - Organização dos } \\
\text { atendimentos } \\
\text { - Favorecer o acesso } \\
\text { do usuário ao serviço } \\
\text { - Logística eficiente } \\
\text { para atendimento aos } \\
\text { usuários } \\
\text { - Atendimento eficaz e } \\
\text { de qualidade }\end{array}$ & $\begin{array}{l}\text { - Facilidade e agilidade } \\
\text { de atendimento } \\
\text { - Atendimento no tempo } \\
\text { adequado } \\
\text { - Logística eficiente para } \\
\text { tempo de espera } \\
\text { - Evitar filas de espera } \\
\text { - Limite do número } \\
\text { atendimentos } \\
\text { - Prazo cumprir serviços } \\
\text { - Respeitar horário }\end{array}$ & 15 & $\begin{array}{l}\text { “Logística eficiente para } \\
\text { atendimento aos usuários, } \\
\text { voltada principalmente para } \\
\text { o horário das consultas, } \\
\text { tempo de espera do } \\
\text { atendimento, acesso, } \\
\text { divulgação, e campanha de } \\
\text { promoção à saúde”. }\end{array}$ \\
\hline $\begin{array}{l}\text { Relação entre os } \\
\text { trabalhadores e } \\
\text { as equipes }\end{array}$ & $\begin{array}{l}\text { - Integração entre } \\
\text { equipes } \\
\text { - Contato entre } \\
\text { equipes } \\
\text { - Melhorar as relações } \\
\text { entre os próprios } \\
\text { profissionais } \\
\text { - Aprimorar as } \\
\text { relações entre os } \\
\text { profissionais }\end{array}$ & $\begin{array}{l}\text { - Formação de grupos } \\
\text { de trabalho objetivando } \\
\text { a transformação dos } \\
\text { vínculos existentes } \\
\text { - Criar formas de } \\
\text { discussão para } \\
\text { simbolizar a equipe }\end{array}$ & 6 & $\begin{array}{c}\text { "Aprimorar as relações entre } \\
\text { os profissionais, pacientes e } \\
\text { instituição, favorecendo o } \\
\text { dialogo e a convivência dos } \\
\text { mesmos". }\end{array}$ \\
\hline $\begin{array}{l}\text { Instrumentalizaçã } \\
\text { o/ capacitação de } \\
\text { profissionais e } \\
\text { equipes }\end{array}$ & $\begin{array}{l}\text { - Capacitação e } \\
\text { acompanhamento } \\
\text { dos } \\
\text { profissionais/servidor } \\
\text { es } \\
\text { - Ofertas de cursos } \\
\text { - Treinamentos } \\
\text { - Treinamento dos } \\
\text { porteiros e } \\
\text { atendentes }\end{array}$ & $\begin{array}{l}\text { - Treinar a equipe, } \\
\text { incentivar cursos na } \\
\text { área } \\
\text { - Profissionais treinados } \\
\text { - Treinamento adequado } \\
\text { da equipe }\end{array}$ & 8 & $\begin{array}{l}\text { "Estabelecer políticas de } \\
\text { capacitação e } \\
\text { acompanhamento dos } \\
\text { profissionais" }\end{array}$ \\
\hline $\begin{array}{l}\text { Ações de } \\
\text { promoção da } \\
\text { saúde }\end{array}$ & $\begin{array}{l}\text { - Ações de promoção da } \\
\text { - Campanha de promoç }\end{array}$ & $\begin{array}{l}\text { saúde } \\
\text { o à saúde }\end{array}$ & 3 & $\begin{array}{c}\text { "Organizar os atendimento e } \\
\text { as ações de promoção da } \\
\text { saúde de modo a favorecer } \\
\text { o acesso do usuário ao } \\
\text { serviço". }\end{array}$ \\
\hline $\begin{array}{l}\text { Valorização do } \\
\text { profissional }\end{array}$ & $\begin{array}{l}\text { - Valorizar o } \\
\text { profissional } \\
\text { - Valorização dos } \\
\text { profissionais } \\
\text { - Aumento de salário }\end{array}$ & $\begin{array}{l}\text { - Melhores salários } \\
\text { - Remuneração } \\
\text { compatível à função } \\
\text { exercida }\end{array}$ & 5 & $\begin{array}{c}\text { "Valorizar o profissional e } \\
\text { seu trabalho, demonstrando } \\
\text { sua importância". }\end{array}$ \\
\hline $\begin{array}{l}\text { Infraestrutura } \\
\text { para o trabalho } \\
\text { em saúde }\end{array}$ & $\begin{array}{l}\text { - Condições físicas } \\
\text { adequadas } \\
\text { - Condições dignas de } \\
\text { trabalho } \\
\text { - Boas condições de } \\
\text { trabalho e do próprio } \\
\text { espaço físico }\end{array}$ & $\begin{array}{l}\text { - Ambiente físico bem } \\
\text { cuidado } \\
\text { - Infraestrutura, espaço } \\
\text { físico adequado } \\
\text { - Ambiente adequado de } \\
\text { trabalho }\end{array}$ & 11 & $\begin{array}{c}\text { "Organização interna, } \\
\text { infraestrutura, profissionais } \\
\text { treinados, espaço físico } \\
\text { adequado". }\end{array}$ \\
\hline
\end{tabular}

Legenda: $\mathrm{N}$ - número de ocorrências 
Quanto às necessidades/demandas para garantia do atendimento humanizado tendo como referência o ambiente de trabalho, as categorias identificadas baseadas nas respostas das entrevistadas, observadas na figura 5, foram: garantia de condições estruturais e de higiene e micropolítica das relações e gestões do trabalho multiprofissional e intersetorial.

Quanto às necessidades/demandas para garantia do atendimento humanizado tendo como referência o usuário, as categorias identificadas baseadas nas respostas das entrevistadas foram: conhecimento dos direitos pelos usuários, responsabilidade do usuário, respeito das demandas e direitos do usuário e respeito às regras, normas e demandas dos profissionais pelos usuários, conforme apresentado na figura 6 .

Quanto às necessidades/demandas para garantia do atendimento humanizado tendo como referência o profissional, as categorias identificadas baseadas nas respostas das entrevistadas foram: investimento no trabalho em equipe, compromisso com formação e instrumentalização profissional e respeito ao usuário, apresentado na figura 7.

\begin{tabular}{|c|c|c|c|c|}
\hline Categorias & \multicolumn{2}{|c|}{ Conteúdos } & $\mathbf{N}$ & Vinhetas \\
\hline $\begin{array}{l}\text { Garantia de } \\
\text { condições } \\
\text { estruturais e de } \\
\text { higiene }\end{array}$ & $\begin{array}{l}\text { - Limpo, com } \\
\text { temperatura adequada, } \\
\text { estrutura física } \\
\text { - Condições de completa } \\
\text { higiene } \\
\text { - Limpeza, iluminação e } \\
\text { acústicas adequadas } \\
\text { - Organização do } \\
\text { ambiente } \\
\text { - Ambiente organizado } \\
\text { - Ambiente agradável } \\
\text { - Condições físicas } \\
\text { adequadas } \\
\text { - Melhor espaço físico }\end{array}$ & $\begin{array}{l}\text { - Organização } \\
\text { - Sala de espera } \\
\text { confortável } \\
\text { - Condições estruturais } \\
\text { - Ambientes tranqüilos } \\
\text { - Banheiros masculinos e } \\
\text { femininos com acesso } \\
\text { para deficientes físicos } \\
\text { - Ambiente de Trabalho } \\
\text { adequado } \\
\text { - Minimizar os riscos e } \\
\text { perigos de um ambiente } \\
\text { de trabalho }\end{array}$ & 17 & $\begin{array}{c}\text { “Ambiente organizado, } \\
\text { limpo, com temperatura } \\
\text { adequada. Estrutura física } \\
\text { (desde a arquitetura ao } \\
\text { design de interior) voltados } \\
\text { para o atendimento à } \\
\text { saúde" }\end{array}$ \\
\hline $\begin{array}{l}\text { Micropolítica } \\
\text { das relações e } \\
\text { gestão do } \\
\text { trabalho } \\
\text { multiprofis- } \\
\text { sional e } \\
\text { intersetorial }\end{array}$ & $\begin{array}{l}\text { - Interação, entre os } \\
\text { outros setores } \\
\text { - Discussão entre todos } \\
\text { os membros, não só } \\
\text { entre médicos } \\
\text { - Discussão entre todos } \\
\text { os envolvidos } \\
\text { - Maior diálogo entre } \\
\text { profissionais } \\
\text { - Discussão de tensões, } \\
\text { dificuldade, etc. }\end{array}$ & $\begin{array}{l}\text { - Cordialidade entre } \\
\text { colegas } \\
\text { - Discussão integrada } \\
\text { com relação ao caso } \\
\text { - Bom relacionamento } \\
\text { entre funcionários } \\
\text { - Interação entre os } \\
\text { profissionais } \\
\text { - Reuniões periódicas } \\
\text { - Trabalho multidisciplinar } \\
\text { - Interdisciplinar }\end{array}$ & 12 & $\begin{array}{c}\text { "Possibilidade de } \\
\text { discussão entre todos os } \\
\text { envolvidos quanto a casos, } \\
\text { condutas, educação } \\
\text { continuada e gestão". }\end{array}$ \\
\hline
\end{tabular}

Legenda: $\mathrm{N}$ - número de ocorrências

Figura 5 - Categorias, conteúdos e apresentação de vinhetas elencadas no relato das fonoaudiólogas quanto ao necessário para um atendimento Humanizado do ponto de vista do ambiente de trabalho 


\begin{tabular}{|c|c|c|c|}
\hline Categorias & Conteúdos & $\mathbf{N}$ & Vinhetas \\
\hline $\begin{array}{l}\text { Conhecimento } \\
\text { dos direitos pelos } \\
\text { usuários }\end{array}$ & $\begin{array}{l}\text { - Busca pelos seus direitos } \\
\text { - Conhecimento e compreensão sobre seus direitos } \\
\text { - Conhecimento dos seus direitos } \\
\text { - Direito de ser atendido com qualidade } \\
\text { - Direitos }\end{array}$ & 7 & $\begin{array}{l}\text { "Conhecimento dos seus } \\
\text { direitos como cidadão" }\end{array}$ \\
\hline $\begin{array}{l}\text { Responsabilidade } \\
\text { do usuário }\end{array}$ & $\begin{array}{l}\text { - Corresponsabilidade sobre seus problemas } \\
\text { - Responsabilidade } \\
\text { - Responsáveis pelo seu atendimento }\end{array}$ & 3 & $\begin{array}{l}\text { "Corresponsabilização } \\
\text { sobre seus problemas" }\end{array}$ \\
\hline $\begin{array}{l}\text { Respeito das } \\
\text { demandas e } \\
\text { direitos do } \\
\text { usuário }\end{array}$ & $\begin{array}{l}\text { - Respeitar opiniões, queixas e necessidades do } \\
\text { paciente } \\
\text { - Postura e respeito ao usuário quanto cidadão } \\
\text { - Respeitado com relação ao agendamento e } \\
\text { realização de exame } \\
\text { - Ser devidamente acolhido } \\
\text { - Projeto de acolhimento do usuário } \\
\text { - Atendimento com qualidade } \\
\text { - Ser atendido com qualidade } \\
\text { - Atendimento mais humano }\end{array}$ & 8 & $\begin{array}{c}\text { "Acolher, ouvir, } \\
\text { compreender, respeitar as } \\
\text { opiniões, queixas e } \\
\text { necessidades do paciente" }\end{array}$ \\
\hline $\begin{array}{l}\text { Respeito às } \\
\text { regras, normas e } \\
\text { demandas dos } \\
\text { profissionais } \\
\text { pelos usuários }\end{array}$ & $\begin{array}{l}\text { - Respeitar os horários } \\
\text { - Respeitar as regras da instituição } \\
\text { - Seguir as regras da instituição } \\
\text { - Respeitar as normas da instituição } \\
\text { - Respeito à instituição e ao profissional } \\
\text { - Competência e ética respeitada } \\
\text { - Respeitar os profissionais que trazem os cuidados } \\
\text { - Acolhimento dos profissionais }\end{array}$ & 8 & $\begin{array}{l}\text { "Respeitar os horários; } \\
\text { respeitar as regras da } \\
\text { instituição; - ser cordial" }\end{array}$ \\
\hline
\end{tabular}

Legenda: $\mathrm{N}$ - número de ocorrências

Figura 6 - Categorias, conteúdos e apresentação de vinhetas elencadas no relato das fonoaudiólogas quanto ao necessário para um atendimento Humanizado do ponto de vista do usuário

\begin{tabular}{|c|c|c|c|}
\hline Categorias & Conteúdos & $\mathbf{N}$ & Vinhetas \\
\hline $\begin{array}{l}\text { Investimento no } \\
\text { trabalho em } \\
\text { equipe }\end{array}$ & $\begin{array}{l}\text { - Trabalho em equipe } \\
\text { - Integração com outra equipe } \\
\text { - Envolvimento com os outros profissionais } \\
\text { - Trocas de informação } \\
\text { - Visão interdisciplinar de trabalho } \\
\text { - Boas relações no ambiente de trabalho }\end{array}$ & 7 & $\begin{array}{l}\text { "Trabalho em equipe, que } \\
\text { haja importância do trabalho } \\
\text { e do conhecimento de cada } \\
\text { uma das profissões e uma } \\
\text { complementação entre eles" }\end{array}$ \\
\hline $\begin{array}{l}\text { Compromisso com } \\
\text { a formação e } \\
\text { instrumentalização } \\
\text { profissional }\end{array}$ & $\begin{array}{l}\text { - Formação continuada } \\
\text { - Conhecimento sobre os processos de trabalho } \\
\text { - Estar sempre informado sobre as novidades de } \\
\text { sua área de atuação } \\
\text { - Conhecimento de cada uma das profissões } \\
\text { - Oficinas com as Unidades Funcionais } \\
\text { - Atenção atualizada } \\
\text { - Conhecimento teórico prático }\end{array}$ & 7 & $\begin{array}{c}\text { "Conhecimento amplo sobre } \\
\text { os processos relacionados à } \\
\text { díade saúde/doença e sobre } \\
\text { as relações humanas" }\end{array}$ \\
\hline $\begin{array}{l}\text { Respeito ao } \\
\text { usuário }\end{array}$ & $\begin{array}{l}\text { - Respeitar o usuário } \\
\text { - Respeitar as necessidades do paciente } \\
\text { - Respeito ao paciente } \\
\text { - Deve proporcionar ao usuário respeito }\end{array}$ & 4 & $\begin{array}{l}\text { "Respeitar o usuário sob } \\
\text { seus aspectos } \\
\text { biopsicossociais, responder } \\
\text { às demandas de saúde e } \\
\text { outras questões" }\end{array}$ \\
\hline
\end{tabular}

Legenda: $\mathrm{N}$ - número de ocorrências

Figura 7 - Conteúdos e apresentação de vinhetas elencadas no relato das fonoaudiólogas quanto ao necessário para um atendimento Humanizado do ponto de vista do profissional 


\section{DISCUSSÃO}

Ao considerar o projeto do Sistema Único de Saúde no Brasil como uma política de construção da democracia, que visa desenvolver relações mais lineares na construção e na gestão do processo de saúde-doença e promover inclusão social e redução de desigualdades, é de suma importância discutir a formação e o perfil dos recursos humanos da saúde e sua interrelação com a população atendida.

Baseado nessa concepção o processo de implantação, avaliação e monitoramento da Política Nacional de Humanização deve ser discutido criticamente e tomado como compromisso de cada categoria profissional e o do universo dos trabalhadores da saúde e das instituições e equipamentos de formação em saúde. Deste modo, a discussão aqui apresentada é uma tentativa de suscitar o debate acerca do compromisso de fonoaudiólogos com processo de humanização da atenção em saúde.

\section{Dos resultados referentes à caracterização da amostra}

Conhecer os sujeitos e suas histórias deve anteceder a discussão de suas impressões, escolhas e discursos. Assim, a discussão dos dados de caracterização da amostra tem como objetivo consubstanciar a compreensão das respostas e conteúdos dos sujeitos participantes do estudo.

A análise da amostra quanto ao tempo de formação e prestação de serviços em outras instituições, mostrou que a maior parte das fonoaudiólogas são graduadas há mais de 5 anos e atuam também em outras instituições. Assim apresentam experiência de prática clínica no setor público e privado. Estas experiências podem garantir e promover a expansão e aprofundamento de conhecimentos e vivências de diretrizes, ações, projetos e programas em hospitais públicos e privados. Os dados revelam, ainda, que as fonoaudiólogas apresentam maior experiência clínica quando comparada às práticas coletivas e corroboram estudos que discutem a formação e a prática do fonoaudiólogo ainda muito voltada à clínica em detrimento da saúde coletiva ${ }^{10}$. As instituições de ensino precisam, portanto, introduzir nos programas educacionais, voltados para a formação do fonoaudiólogo, modelos e práticas de saúde coletiva.

A análise do perfil das fonoaudiólogas em relação à formação evidenciou que a maioria investiu e investe em atividade de educação continuada e permanente o que deve impactar positivamente as atividades assistenciais e de gestão. Além disso, parte da amostra é, também docente no curso de Fonoaudiologia da instituição e portanto, apresenta formação acadêmica (mestrado e doutorado). Tal dado aproxima a formação dos estudantes das práticas clínicas e de gestão na instituição. Entendese que a pós-graduação tem como perfil a formação de docentes de ensino superior capazes de traçar estratégias de planejamento e gestão do conhecimento em consonância com as práticas clínicas desenvolvidas na instituição ${ }^{11}$.

\section{Dos resultados referentes ao conhecimento da Política Nacional de Humanização}

Em face do conceito de humanização divulgado e preconizado por esferas do governo e da própria instituição, ao verificar que $60 \%$ da amostra referem conhecer a Política Nacional de Humanização, cabe avaliar a implicação deste dado na prática assistencial e no conhecimento e aplicação das políticas de saúde. Cabe ressaltar que os dados de conhecimentos / desconhecimento da PNH não necessariamente se traduzem em relações e práticas mais ou menos humanizadas. Cabe ainda, considerar que nem sempre o conhecimento formal de um conceito garante sua instituição e aplicação. Contudo, o conhecimento e apropriação do conceito é a primeira etapa a ser garantida antes da incorporação na prática. No presente estudo deve ser vista como positiva a amostra de fonoaudiólogos que referiu conhecer a $\mathrm{PNH}$.

A análise dos conteúdos das respostas apresentadas pelas fonoaudiólogas quanto ao conceito de humanização, revelou que o atendimento integral, a qualidade de vida e o acolhimento são categorias destacadas. Percebe-se que as fonoaudiólogas demonstram acreditar que para garantia do atendimento humanizado é necessário oferecer atendimento integral com equidade, em todas as práticas profissionais, e considerar cada usuário como ser indivisível sem possibilidades de desvincular biológico, psíquico, espiritual e social. A qualidade da atenção deve demonstrar o respeito que se tem pelo indivíduo/pelo sujeito. $\mathrm{O}$ acolhimento ou valorização do usuário enquanto sujeito do processo saúde/ doença garante o cuidado com o outro, proporcionando relações mais saudáveis, assim como maior efetividade do atendimento. Estes achados indicam que as fonoaudiólogas participantes da pesquisa destacam a importância de existir uma assistência integral que busque resolver problemas e necessidades de saúde do usuário conforme enfatizado pela literatura ${ }^{1}$ e contribuir positivamente para a qualidade da atenção, comunicação e integração entre profissionais e usuários ${ }^{12}$. Tais dados corroboram ainda diversos estudos ${ }^{7,13-17}$.

A análise dos conteúdos das respostas apresentadas pelas fonoaudiólogas quanto o necessário para um atendimento Humanizado, tendo 
como referência a instituição, revelou que o acesso e organização dos serviços, a relação entre os trabalhadores e as equipes, a instrumentalização/ capacitação de profissionais e equipes, as ações de promoção da saúde, valorização do profissional e infra-estrutura para o trabalho em saúde foram as categorias enfatizadas. Estes achados demonstram que os sujeitos de pesquisa entendem as dimensões e implicações da incorporação da $\mathrm{PNH}$ no perfil organizacional e a valorização dos espaços de trabalho em equipe como parte do processo de humanização da assistência.

Vale dizer que a instituição deveria lançar mão de estratégias que propiciem, no processo administrativo e burocrático, maior efetividade dos serviços. Para tanto, é fundamental propiciar a capacitação do trabalhador em saúde, quanto à gestão do trabalho e capacitação técnica e assistencial, dando a ele oportunidade de conhecer e valorizar suas atividades. ${ }^{17-20}$ Deste modo, a promoção do cuidado também seria resultado da valorização e capacitação do trabalhador da saúde.

As necessidades relatadas pelas fonoaudiólogas corroboram estudos que relatam a necessidade de criação de uma PNH que traga mudanças nos modelos de atenção e gestão em saúde, amparando usuários e servidores, assim como garantindo um espaço físico, administrativo e ambiental digno $^{2,7}$. Considerar a PNH na escolha e gestão de estratégias e projetos assistenciais de saúde é fundamental para amparar o trabalhador e o próprio projeto institucional 2,6,7,12, 18-21.

A análise dos conteúdos quanto ao necessário para um atendimento humanizado, tendo como referência o ambiente de trabalho, demonstrou que a garantia de condições estruturais, de higiene, a micropolítica das relações e gestão do trabalho multiprofissional e intersetorial foram categorias predominantes. Em face das respostas, para um desempenho positivo dos servidores, estes devem contar com uma infra-estrutura física, de higiene, ambiental e de relacionamento que beneficie e facilite as suas atividades e serviços prestados. Neste caso, vale lembrar a experiência realizada em outro hospital, que trouxe como resultado a possibilidade de obter mudanças positivas nos serviços saúde, quando o trabalho de organização dos mesmos é desenvolvido em equipe ${ }^{19}$.

Os dados referentes às demandas do ambiente de trabalho corroboram, ainda, estudos que enfatizaram o papel do ambiente de trabalho na garantia de condições assistenciais adequadas e do processo de trabalho humanizado e humanizador, que lembram da necessidade de união e comprometimento de trabalhadores e usuários para o cumprimento de tais demandas ${ }^{2,21,22}$.
As respostas apresentadas quanto o necessário para um atendimento Humanizado, tendo como referência o usuário, evidenciaram a importância do usuário conhecer seus direitos e deveres, os direitos e deveres dos trabalhadores, além de respeitar regras, normas instituição. Com isto, percebese também que grande parte das fonoaudiólogas ressalta o cumprimento dos direitos e deveres dos usuários, enquanto outras demandam responsabilidade ao usuário quanto aos procedimentos. Cabe ressaltar que a responsabilidade principal pelos procedimentos e práticas assistenciais não deve ser delegada ao usuário pois este, muitas vezes, não tem poder ou não é considerado no processo decisório das ações profissionais. O que deve ser analisado e discutido é o processo de vinculação e desvinculação e apropriação do usuário. Assim, deve-se olhar com cuidado as respostas de parte das fonoaudiólogas que delegaram ao usuário a responsabilidade pela adequação dos procedimentos assistenciais. Sabe-se que a participação do usuário é fundamental no processo de assistência, mas ele não pode ser responsabilizado pela adequação ou não dos procedimentos prestados. Alguns estudos enfatizam a necessidade de considerar o usuário como protagonista do processo de atenção em saúde, mas em nenhum deles o processo de responsabilização é retirado do profissional $^{3,14,23}$. Assim, cabe destacar achados que ressaltam a importância da preparação e participação dos usuários e dos técnicos nos processos assistenciais, para garantir acolhimento e processo de recuperação mais rápido ${ }^{3,23}$. Médicos que foram em algum momento pacientes, relataram ter vivenciado a sensação de perda dos seus direitos, além da falta de apoio psicológico por parte dos profissionais da área, trazendo então a importância da participação do usuário para atendimento mais humanizado ${ }^{14}$.

É preciso destacar a parte da amostra que elencou a vinculação entre profissional e usuário no processo assistencial e como esta vinculação pode favorecer atenção integral e práticas mais humanizadas $\mathrm{O}$ atendimento integral cria um vínculo entre o profissional e o usuário ${ }^{1}$. Ao conhecer melhor o usuário o profissional obtém maior conhecimento sobre o indivíduo. Por outro lado, há estudos que contam da experiência de encontrar passividade e resignação em alguns sujeitos (usuários) entrevistados frente aos seus direitos como cidadãos ${ }^{19}$. Os dados referentes às demandas do usuário corroboram, ainda outros estudos $4,5,15,17,24,25$.

A análise dos conteúdos quanto ao necessário para um atendimento Humanizado, tendo como referência o profissional, evidenciou como categorias o investimento no trabalho em equipe, 
compromisso com a formação e instrumentalização profissional e respeito ao usuário. Devemse considerar estas categorias como essenciais, uma vez que, para ter o atendimento humanizado, é indispensável à instrumentalização e formação permanente dos servidores. Quando há equilíbrio entre tecnologia, formação e construção de identidade profissional, se oferece ao trabalhador apropriação, segurança e satisfação frente às ações e projetos desenvolvidos.' Os dados aqui elencados corroboram autores que revelam a importância da discussão entre tecnologia das relações, processo de cuidado e do trabalho em saúde na garantia do acesso e da humanização das práticas de saúde $^{14 ;}$ e enfatizam a necessidade de mudanças nos processos de trabalho ${ }^{26-28}$, no caso do estudo em partos, para garantir os direitos da mulher e sua família ${ }^{29}$. O conhecer e ter habilidade de tratamento interpessoal auxilia na comunicação e interação entre profissional e usuário, garantindo maior abrangência e eficácia no tratamento ${ }^{17}$.

$\mathrm{Na}$ literatura compulsada foram encontrados estudos que lembram a importância da construção de um projeto coletivo, da formação profissional e da atualização permanente em equipe e da equipe para o estabelecimento de práticas humanizadas e humanizadoras ${ }^{7,17,21,29-37}$. A literatura aponta que a $\mathrm{PNH}$ deve favorecer a mudança de rotinas, práticas e, sobretudo a relação entre usuários, profissionais e gestores ${ }^{38}$.

As fonoaudiólogas que participaram do estudo consideraram o conhecimento da Política Nacional de Humanização (PNH) como elemento essencial para o desenvolvimento de programas humanizadores que propiciem a relação efetiva entre usuário, profissionais e instituição.

No presente estudo, a discussão da Política Nacional de Humanização aliada a prática fonoaudiológica, pode ser considerada relevante e pode, ainda contribuir no avanço na investigação na área de saúde coletiva, sobretudo e na interface com a gestão e avaliação de serviços assistenciais. Apesar das contribuições do estudo, foram observadas algumas limitações durante a sua realização. Duas delas foram o tamanho e o delineamento da amostra, visto que foram analisadas percepções de fonoaudiólogos de apenas uma instituição. Além disso, a amostra de conveniência impede generalizações dos achados.

Dados como os aqui apresentados podem ser relevantes para a prática fonoaudiológica, pois é possível a consideração dos achados como eixos de discussão na estruturação da assistência e na construção de atendimentos de qualidade e efetivos. Podem ainda contribuir na discussão da garantia, da valorização e priorização do outro no encontro entre "usuário-cidadão", "profissionalcidadão" e instituição comprometida.

\section{CONCLUSÕES}

Frente aos achados da pesquisa foi considerado pertinente concluir que a maioria das entrevistadas, graduada em Fonoaudiologia há mais de cinco anos, refere conhecer a Política Nacional de Humanização (PNH). O conceito de humanização apontado pela amostra perpassa os conceitos de atendimento integral, acolhimento e qualidade de vida.

As necessidades/demandas apontadas para garantia do atendimento humanizado tendo como referência constou dos eixos temáticos gestão e organização dos serviços de saúde, instrumentalização do trabalhador da saúde, inclusão de práticas multiprofissionais e intersetoriais, além do respeito às demandas e direitos do usuário. 


\begin{abstract}
Purpose: to investigate speech therapists knowledge and application as for the National Policy of Humanization (NPH) in a public hospital in Belo Horizonte Method: it is a qualitative and qualitative study. With 25 speech therapists answering a self-applicable questionnaire, used as instrument for data collection, elaborated by the authors. A quantitative analysis was carried through on the questions referring to sample characterization and also a qualitative analysis of the content, through which the categories of analysis were identified and ranked, as well as contents' frequency as for the occurrence and expressions being used. Results: it was possible to perceive in the quantitative analysis that $68 \%$ of speech therapists had been graduated for more than five years; $88 \%$ were post-graduated; $52 \%$ also acted in private institutions and $60 \%$ declared being familiar with NPH. In the qualitative analysis, content was organized in the following categories: service organization; instruments used for professionals and team training; management of multi professional and intersector works. Conclusion: in what concerns the concept of humanization presented by the speech therapists, it is in consonance with what has been described in the National Politic of Humanization. About the criteria needed in order to guarantee a humanized assistance taking as reference the institution, the user and the professional, the interviewed subjects partially cited the principles of the National Policy of Humanization.
\end{abstract}

KEYWORDS: Humanization of Assistance; Public Health; Unified Health System; Tertiary Health Care; Health Knowledge, Attitudes, Practice

\section{REFERÊNCIAS}

1. Mattos RA. Princípios do Sistema Único de Saúde (SUS) e humanização das práticas de saúde. Rev Intertaface. 2009; 13(1): 1414 -3283.

2. Benevides R, Passos E. A humanização como dimensão pública das políticas de saúde. Ciênc. saúde coletiva. 2005;10(3):561-71.

3. Beck CLC, Lisbôa RL, Tavares JP, Silva RM, Prestes FC. Humanização da assistência de enfermagem: percepção de enfermeiros nos serviços de saúde de um município. Rev Gaucha Enferm. 2009 mar;30(1):54-61.

4. Cardoso PR. Humanização em terapia intensiva: um estudo compreensivo com os profissionais que assistem crianças [tese]. Belo Horizonte(MG): Universidade Federal de Minas Gerais; 2001.

5. Oliveira BRG, Collet N, Viera CS. A humanização na assistência à saúde. Rev. Latino-Am. Enfermagem. 2006;14(2):277-84.

6. Puccini PT, Cecílio LCO. A humanização dos serviços e o direito à saúde. Cad. Saúde Pública. 2004;20(5):1342-53.

7. Backes DS, Lunardi VL, Lunardi Filho WD. A humanização hospitalar como expressão da ética. Rev. Latino-Am. Enfermagem. 2006;14(1):132-5.

8. Muccioli C, Campos MSQ, Dantas PEC, Goldchmit $\mathrm{M}$, Bechara SJ, Costa VP, et al. A humanização da medicina. Arq. Bras. Oftalmol. 2007;70(6):897.
9. Caregnato RCA, Mutti, R. Pesquisa qualitativa: análise de discurso versus análise de conteúdo. Texto contexto - enferm. [online]. 2006.15(4): 679-84.

10. Mendes VLF. Acesso á saúde em Fonoaudiologia. In: Befi-Lopes DM. Fonoaudiologia na Atenção Primária à Saúde. Vol. III. São Paulo: Lovise. 1997; p. 43-56.

11. Ceccim RB. Educação Permanente em Saúde: descentralização e disseminação de capacidade pedagógica na saúde. Ciênc. saúde coletiva. 2005;10(4):975-86.

12. Deslandes SF, Mitre RMA. Processo comunicativo e humanização em saúde. Rev Interface. 2009;13(1): 641-9.

13. Neto JACN, Soares GMTS, Delgado AAA, Lima JV, Beligoli DA, Mello CS. Informações em saúde e a população: a relação médico-paciente e as repercussões no tratamento. HU Revista. 2010 jan/ mar;36(1) : 13-8.

14. Sucupira AC. A importância do ensino da relação médico-paciente e das habilidades de comunicação na formação do profissional da saúde. Rev Interface. 2007;11(23):624-7.

15. Coelho MO, Jorge MSB. Tecnologia das relações como dispositivo do atendimento humanizado na atenção básica à saúde na perspectiva do acesso, do acolhimento e do vínculo. Ciên. Saúde coletiva. 2009; 14(1) : 1523-31. 
16. Pereira MGA, Azevêdo ES. A relação médicopaciente em Rio Branco/AC sob a ótica dos pacientes. Rev. Assoc. Med. Bras. 2005;51(3):153-7. 17. Goulart BNG, Chiari BM. Avaliação clínica fonoaudiológica, integralidade e humanização: perspectivas gerais e contribuições para reflexão. Rev. soc. bras. fonoaudiol. 2007 Dez;12(4):335-40. 18. Traverso-Yépez M, Morais NA. Reivindicando a subjetividade dos usuários da rede básica de saúde: para uma humanização do atendimento. Cad. Saúde Pública. 2004 ;20(1):80-8.

19. Costa JSM. Assistência humanizada e estrutura organizativa. A necessária interface: a experiência do grupo de trabalho de humanização em um hospital de Belo Horizonte [tese]. Belo Horizonte(MG): Universidade Federal de Minas Gerais; 2004.

20. Backes DS, Lunardi Filho WD, Lunardi VL. O processo de humanização do ambiente hospitalar centrado no trabalhador. Rev. Esc. Enferm. 2006;40(2):221-7.

21. Mota RA, Martins, CG de M, Veras RM. Papel dos profissionais de saúde na política de humanização hospitalar. Psicol. estud. 2006;11(2):323-30.

22. Falk MLR, Falk JW, Oliveira FA, Motta MS. Acolhimento como dispositivo de humanização: percepção do usuário e do trabalhador em saúde. Rev APS. 2009 jan/mar; 13(1): 4-9.

23. Bergan C, Bursztyn I, Santos MCO, Tura LFR. Humanização: representações sociais do hospital pediátrico. Rev Gaúcha Enferm. 2009 dez; 30(4): 656-61.

24. Brasil. Ministério da Saúde. Humaniza SUS política nacional de humanização. Brasília (DF): Ministério da Saúde; 2004. Disponível em: http:/ www.saúde.gov.br/humanizasus.

25. Vaitsman J, Andrade GRB de. Satisfação e responsividade: formas de medir a qualidade e a humanização da assistência à saúde. Ciênc. saúde coletiva. 2006;10(3): 599-613.

26. González AD, Almeida MJ . Integralidade da saúde - norteando mudanças na graduação dos novos profissionais. Ciência \& Saúde Coletiva, 2010;15(3):757-62.

http://dx.doi.org/10.1590/S1516-18462012005000015

RECEBIDO EM: 10/02/2011

ACEITO EM: 20/07/2011

Endereço para correspondência:

Stela Maris Aguiar Lemos

Departamento de Fonoaudiologia, Faculdade de

Medicina - UFMG

Avenida Alfredo Balena, 190, sala 069

Santa Efigênia - Belo Horizonte - Minas Gerais

CEP: $30130-100$

E-mail: smarislemos@medicina.ufmg.br
27. Machado MFAS, Monteiro EMLM, Queiroz DT, Vieira NFC, Barroso MGT . Integralidade, formação de saúde, educação em saúde e as propostas do SUS - uma revisão conceitual. Ciência \& Saúde Coletiva. 2007; 12(2):335-42.

28. Motta LB , Aguiar AC. Novas competências profissionais em saúde e o envelhecimento populacional brasileiro: integralidade, interdisciplinaridade e intersetorialidade. Ciência \& Saúde Coletiva. 2007; 12(2):363-72.

29. Santos NCP. Conhecimento Técnico Científico Associado à Humanização na Assistência ao Parto: Percepção das Mulheres [tese]. Belo Horizonte(MG): Universidade Federal de Minas Gerais; 2000.

30. Araujo DBG, Peixinho AL. Avaliação efetiva de estudantes como forma de humanização da educação médica. Rev Olho Mágico. 2005;12(2): 120-5.

31. Costa TF, Ribeiro EF, Melo NP. Concepção de humanização na visão da enfermagem em oncologia pediátrica. Nursing.2010;13(146): 343-7. 32. Fontana RT. Humanização no processo de trabalho em enfermagem : uma reflexão.Rev Rene. 2010 jan/mar; 11(1): 200-7.

33. Chiesa AM, Nascimento DDG, Bracciall LAD, Oliveira MAC, Ciampone MHT. Formação de profissionais da saúde: aprendizagem significativa â luz da promoção da saúde . Cogitare Enferm. 2007 Abr/Jun; 12(2):236-40.

34. Goulart BNG, Chiari BM Humanização das práticas do profissional de saúde - contribuições para reflexão Ciência \& Saúde Coletiva, 2010; 15(1):255-68.

35. Junqueira TS, Cotta RMM, Gomes RC, Silveira SFR, Batista RS,Pinheiro TMM, et al. Saúde, democracia e organização do trabalhono contexto do Programa de Saúde da Família:desafios estratégicos. Rev Bras de Educ Médica. 2009; 33 (1) : 122-33.

36. Ferreira MLSM, Cotta RMM, Lugarinho R, Oliveira MS. Construção de Espaço Social Unificado para Formação de Profissionais da Saúde no Contexto do Sistema Único de Saúde Rev Bras de Educ Médica. 2010; 34 (2): 304-9.

37. Mendonça AVM. Informação, educação e comunicação em saúde: resistindo às sereias. Tempus - Actas de Saúde Coletiva. 2009/mar; 3(1):6.

38. Souza LAP, Mendes, VLF.. O conceito de humanização na Política Nacional de Humanização (PNH). Interface (Botucatu) [online]. 2009, vol.13, suppl.1, pp. 681-688. ISSN 1414-3283. 